\title{
A Role for the Equatorial Undercurrent in the Ocean Dynamical Thermostat
}

\author{
S. COATS ${ }^{\mathrm{a}}$ \\ Climate and Global Dynamics Laboratory, National Center for Atmospheric Research, and Cooperative Institute for Research in \\ Environmental Sciences, University of Colorado Boulder, Boulder, Colorado \\ K. B. KARNAUSKAS \\ Cooperative Institute for Research in Environmental Sciences, and Department of Atmospheric and Oceanic Sciences, University of \\ Colorado Boulder, Boulder, Colorado
}

(Manuscript received 1 August 2017, in final form 16 April 2018)

\begin{abstract}
Reconstructions of sea surface temperature (SST) based on instrumental observations suggest that the equatorial Pacific zonal SST gradient has increased over the twentieth century. While this increase is suggestive of the ocean dynamical thermostat mechanism of Clement et al., observations of a concurrent weakening of the zonal atmospheric (Walker) circulation are not. Here we show, using heat and momentum budget calculations on an ocean reanalysis dataset, that a seasonal weakening of the zonal atmospheric circulation is in fact consistent with cooling in the eastern equatorial Pacific (EEP) and thus an increase in the zonal SST gradient. This cooling is driven by a strengthening Equatorial Undercurrent (EUC) in response to decreased upper-ocean westward momentum associated with weakening equatorial zonal wind stress. This process can help to reconcile the seemingly contradictory twentieth-century trends in the tropical Pacific atmosphere and ocean. Moreover, it is shown that coupled general circulation models (CGCMs) do not correctly simulate this process; we identify a systematic bias in the relationship between changes in equatorial surface zonal wind stress in the EEP and EUC strength that may help to explain why observations and CGCMs have opposing trends in the zonal SST gradient over the twentieth century.
\end{abstract}

\section{Introduction}

The mean state of the equatorial Pacific is characterized by a zonal gradient of sea surface temperatures (SST gradient) that is tightly coupled to a zonal atmospheric circulation (the Walker circulation) at interannual time scales (Bjerknes 1969). Despite representing only $\sim 10 \%$ of global surface area, the equatorial Pacific plays an outsized role in the global climate system, with small changes in its mean state sufficient to drive largemagnitude local and remote climate impacts (e.g., Fedorov and Philander 2000; Schubert et al. 2004; Sarachik and Cane 2010; Seager and Vecchi 2010; Kosaka and Xie 2013; Seager et al. 2015). By virtue of this global importance, the change in the mean state of the equatorial Pacific in response to anthropogenic

\footnotetext{
${ }^{\text {a }}$ Current affiliation: Woods Hole Oceanographic Institution, Woods Hole, Massachusetts.
}

Corresponding author: S. Coats, scoats@whoi.edu forcing has received considerable attention in theoretical, observational, and modeling frameworks. Nevertheless, there is little consensus on how the equatorial Pacific has changed over the observational interval (roughly 1870-present) and will change in the future. This is, in part, because of contradictory theoretical outcomes centered on a dominant role for the atmosphere, ocean, or their coupling in determining this mean-state response. For instance, an atmospherecentric theory proposes that the Walker circulation should weaken in response to anthropogenic forcing (Held and Soden 2006; Vecchi and Soden 2007), leading to a decrease in the SST gradient by reducing the strength of wind-driven equatorial upwelling. By contrast, an ocean-centric theory proposes that the SST gradient should increase in response to anthropogenic forcing, because the vertical and meridional ocean circulation in the eastern equatorial Pacific (EEP) should mitigate surface warming, increase the SST contrast with the western Pacific, and strengthen the Walker circulation (Clement et al. 1996; Sun and Liu 1996; 
Seager and Murtugudde 1997). Finally, when the thermodynamic component of atmosphere-ocean coupling is considered, it has been proposed that the SST gradient will decrease because surface evaporative cooling is more effective in the western equatorial Pacific (Xie et al. 2010).

Motivated by these competing theories, efforts have been made to relate observed changes in the equatorial Pacific to anthropogenic forcing. However, there is disagreement over whether observations suggest that the Walker circulation and SST gradient are weakening (Vecchi et al. 2006; Vecchi and Soden 2007; Deser et al. 2010; Tokinaga et al. 2012a,b) or strengthening (Cane et al. 1997; Karnauskas et al. 2009; L'Heureux et al. 2013; Sandeep et al. 2014; Kociuba and Power 2015; Sohn et al. 2016). One reason for this discrepancy is observational uncertainties, which are considerable over the twentieth century and are related to the spatial distribution and frequency of observations (Deser et al. 2010; Giese and Ray 2011; Yasunaka and Hanawa 2011; Kennedy 2014), observation techniques (e.g., Thompson et al. 2008; Tokinaga et al. 2012b), and issues with the statistical methodologies used to reconstruct the SST field from sparse inputs (e.g., Deser et al. 2010). Another is that twentieth-century trends in common metrics of the atmospheric state of the equatorial Pacific appear to be inconsistent with those of the oceanic state, at least given our canonical understanding of coupled atmosphericocean dynamics in this region.

To illustrate this paradox, Figs. 1a and 1b show two metrics based on the climatology of the equatorial $\mathrm{Pa}-$ cific: the SST gradient (SST difference between $2^{\circ} \mathrm{N}-2^{\circ} \mathrm{S}$, $117^{\circ}-173^{\circ} \mathrm{E}$ and $2^{\circ} \mathrm{N}-2^{\circ} \mathrm{S}, 205^{\circ}-275^{\circ} \mathrm{E}$; trends calculated using the HadISST dataset and Rayner et al. 2003) and the sea level pressure gradient [SLP gradient (SLP difference between Tahiti and Darwin); trends calculated using observations from the National Oceanic and Atmospheric Administration (NOAA) Climate Prediction Center (CPC)], the latter of which is a common metric of Walker circulation strength known as the Southern Oscillation index (SOI), which is used here because of the availability of continuous observations over the twentieth century. Trends in the SST gradient and Walker circulation between 1900 and 2008 (Fig. 1c) suggest that the SST gradient has increased while the Walker circulation has weakened (although only the SST gradient trend is statistically significant). This is seemingly inconsistent with our canonical understanding of the equatorial Pacific because the atmosphere and ocean are thought to be tightly coupled over the region, with the SST gradient and Walker circulation largely in phase on interannual time scales.

It should be noted that these metrics represent one of many possible metric choices calculated from a number of potential observational datasets. While twentieth- century SST gradient trends are consistent across observational datasets and for a range of time periods (Solomon and Newman 2012; cf. Fig. 1 and Fig. S5 from Coats and Karnauskas 2017), and SST gradient trends are consistent across a range of metric choices (Coats and Karnauskas 2017), there may still be systematic biases in observational SST datasets (e.g., Deser et al. 2010). These same biases are likely to be present in observational SLP datasets, and Power and Kociuba (2011) suggest that, at least in models, the SOI is not an ideal metric of long-term changes to the Walker circulation. Perhaps most importantly, while the annual and monthly trends in the SST gradient are statistically significant, the annual and many of the monthly trends in the Walker circulation are not. The discussion in the following paragraphs, and more generally in this paper, is thus meant solely to outline the physical mechanisms by which a simultaneous weakening of the Walker circulation and strengthening of the SST gradient is plausible and indeed expected.

Despite observations of a significant year-round increase in the SST gradient, there is no such corresponding strengthening of the Walker circulation, as our canonical understanding would suggest (Fig. 1c). However, there is a distinct seasonality to these trends whereby the Walker circulation trend is positive (strengthening) in boreal autumn and winter (significant in November) and negative in boreal summer (Fig. 1c; significant in June, July, and August). This seasonality is consistent with the ocean dynamical thermostat mechanism as originally posed (Clement et al. 1996), as boreal fall is the season with strongest mean trade wind strength and upwelling in the eastern equatorial Pacific that can counter surface warming, resulting in an increased SST gradient and a strengthened Walker circulation [see gray shading in Fig. 1c for a replication of the Clement et al. (1996) prediction]. However, the significant weakening of the Walker circulation and significant increase in the SST gradient during boreal summer is not consistent with our canonical understanding of coupled atmosphere-ocean dynamics in the equatorial Pacific. Herein we seek to explain this discrepancy, motivated by Sen Gupta et al. (2012) and Drenkard and Karnauskas (2014), in which a long-term strengthening of the Equatorial Undercurrent (EUC) in coupled general circulation models (CGCMs) and an ocean reanalysis, respectively, is attributed to concurrent changes in the tropical wind stress field stemming from a weakening of the Walker circulation.

The EUC is a relatively strong $\left(1 \mathrm{~m} \mathrm{~s}^{-1}\right)$ eastward subsurface countercurrent in the Pacific that is constrained by the Coriolis force to within $2^{\circ}$ latitude of the equator and that shoals from approximately $200 \mathrm{~m}$ in the west to $50 \mathrm{~m}$ in the east (Fig. 2). The zonal momentum 

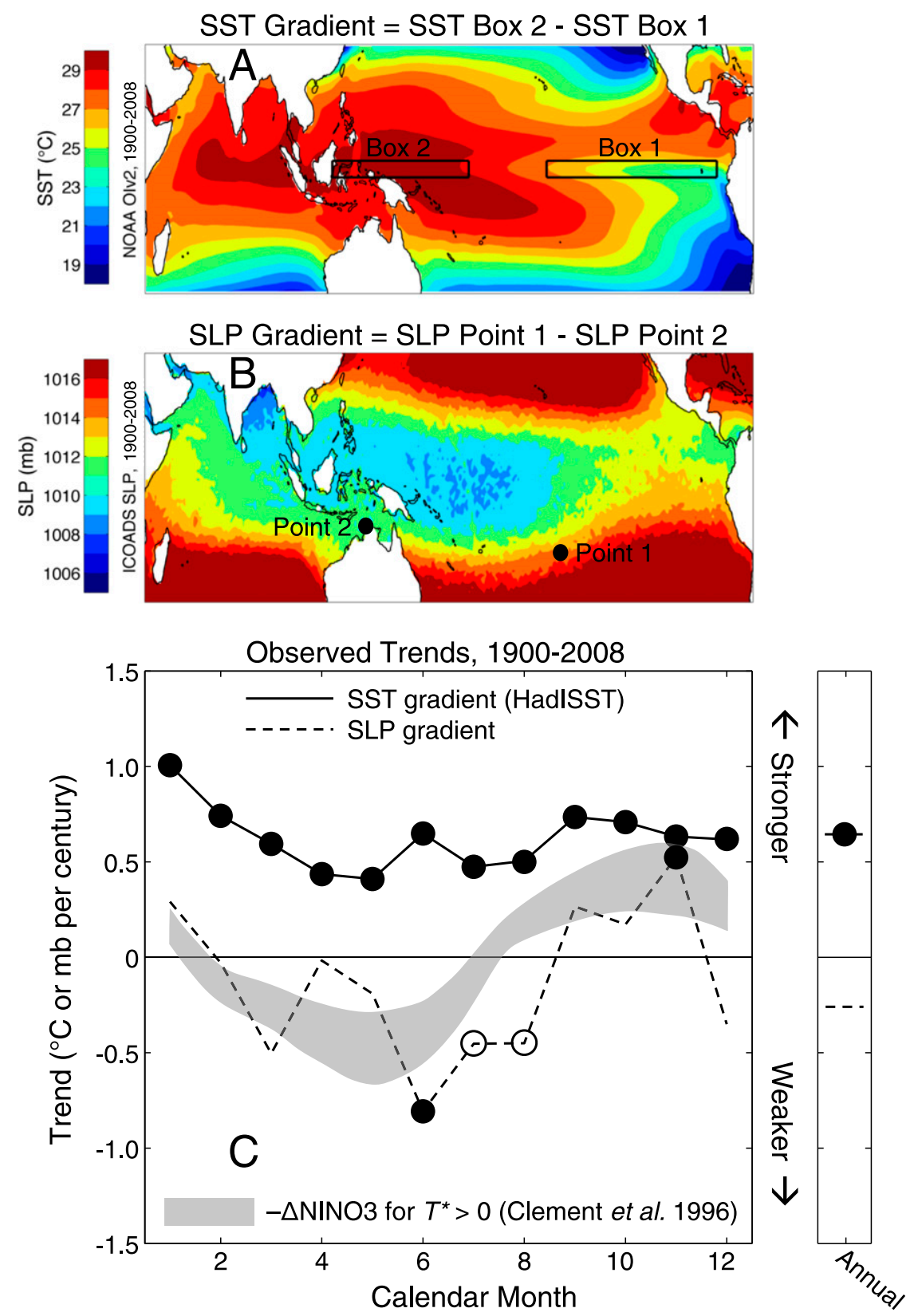

FIG. 1. (a) SST climatology $\left({ }^{\circ} \mathrm{C}\right.$ ) between 1982 and 2013; (b) SLP climatology (mb) between 1982 and 2013; (c) Trend by calendar month and annually for the SST gradient (SST difference between the regions $2^{\circ} \mathrm{N}-2^{\circ} \mathrm{S}, 117^{\circ}-173^{\circ} \mathrm{E}$ and $2^{\circ} \mathrm{N}-2^{\circ} \mathrm{S}, 205^{\circ}-275^{\circ} \mathrm{E}$ ) using HadISST (Rayner et al. 2003) and the observed SLP gradient (SOI; section 2) between 1900 and 2008. All trends are estimated from a linear least squares fit, and filled circles represent trend values with $90 \%$ confidence bounds that do not intersect zero, and open circles represent those with $80 \%$ confidence bounds that do not intersect zero. The gray shaded region is the range in the response $\left({ }^{\circ} \mathrm{C} \times-1\right)$ of the EEP $\left(\mathrm{Niño}-3 ; 5^{\circ} \mathrm{N}-5^{\circ} \mathrm{S}, 150^{\circ}-90^{\circ} \mathrm{W}\right)$ by month to increased forcing $\left(0.5^{\circ}-2^{\circ} \mathrm{C}\right.$ uniform warming; $\left.T^{*}\right)$ in the Zebiak-Cane model (Zebiak and Cane 1987), illustrating the ocean dynamical thermostat mechanism [adapted from Clement et al. (1996)].

balance is maintained by westward surface wind stress at the equator, which drives a westward surface current, westward sea surface height (SSH) gradient, and eastward pressure gradient force. Importantly, the westward surface wind stress also generates a retarding force to the eastward momentum of the EUC, the strength of which is related to depth (Qiao and Weisberg 1997) and, consequently, longitude, given that the EUC shoals 

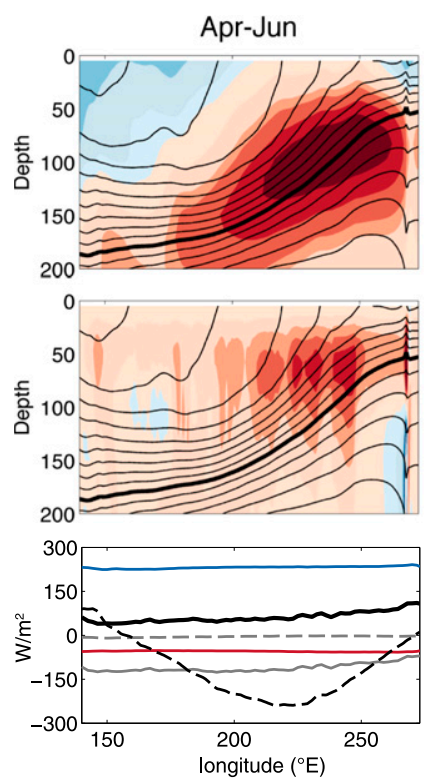

Jul-Sep
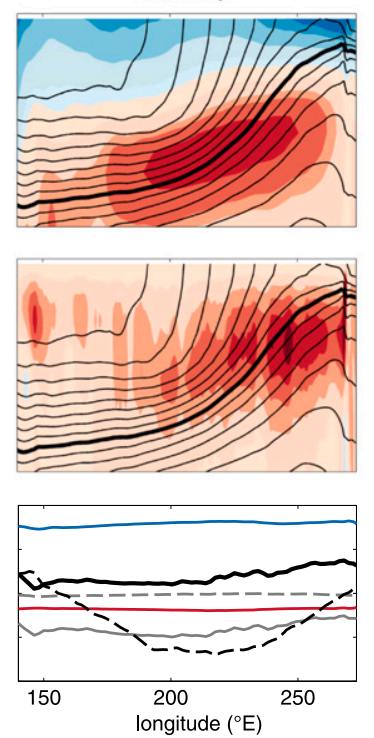

Oct-Dec
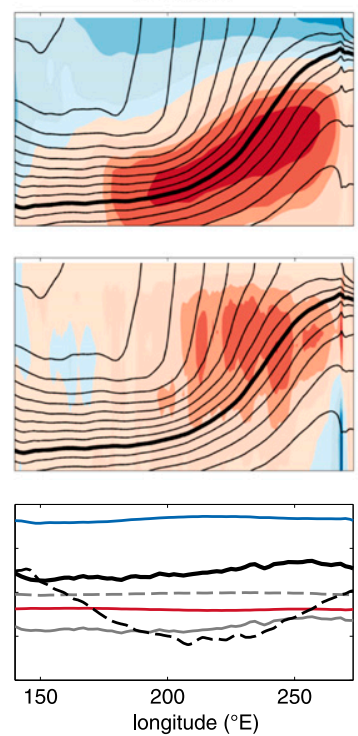

Jan-Mar
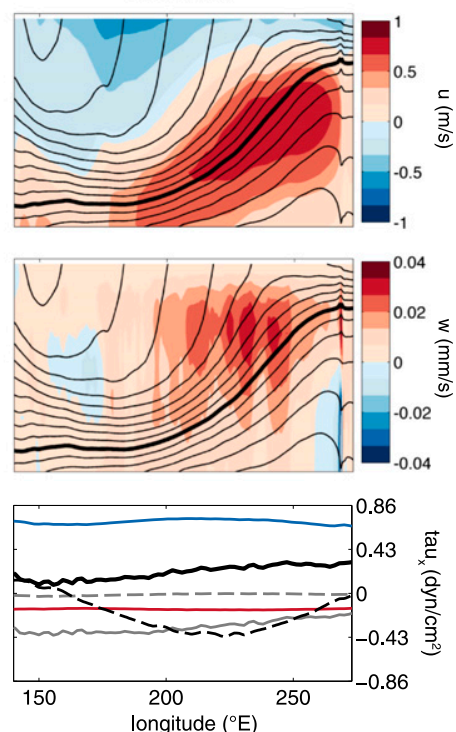

FIG. 2. Equatorial Pacific climatology (averaged over $2^{\circ} \mathrm{S}$ to $2^{\circ} \mathrm{N}$ ) from the ocean reanalysis (SODA, version 2.2.4; Carton and Giese 2008). Temperature contours $\left(1^{\circ} \mathrm{C}\right.$ increments; the thick line is the $20^{\circ} \mathrm{C}$ isotherm) are overlaid on the (top) zonal and (middle) vertical velocity panels. (bottom) Net radiation (thick black), net shortwave radiation (red), net longwave radiation (blue), latent heat (gray), sensible heat (dashed gray), and wind stress (dashed black; right axis).

from west to east. The EUC has considerable seasonality (Fig. 2) and direct measurements show that the EUC outcrops at the surface in the eastern equatorial Pacific in boreal spring through early summer (e.g., Jones 1969; Johnson et al. 2002; see also April-June in Fig. 2) and thus has the potential to directly impact surface properties, particularly during this season. Likewise, the EUC has been identified as the dominant source of upwelled water that sets up the climatological SST gradient (Bjerknes 1966). We therefore hypothesize that the EUC can influence long-term trends in the SST gradient.
Drenkard and Karnauskas (2014) demonstrated that a slight weakening of the Walker circulation over the twentieth century [slight relative to amplitudes associated with El Niño-Southern Oscillation (ENSO)] strengthens the EUC in boreal summer. This is because the acceleration due to the decrease in westward momentum dominates locally in the eastern equatorial Pacific, where the EUC is shallow, over the deceleration due to the decrease in the zonal SSH gradient (and associated decrease in the pressure gradient force; Fig. 3). This process is akin to the so-called springtime surge of

Weaken wind stress

1) $\mathrm{SSH}$ gradient and pressure gradient force decrease - Deceleration

2) Westward momentum decrease - Acceleration

For small changes: Acceleration via 2) > Deceleration via 1) EUC strengthens

West Pacific

East Pacific

Wind stress

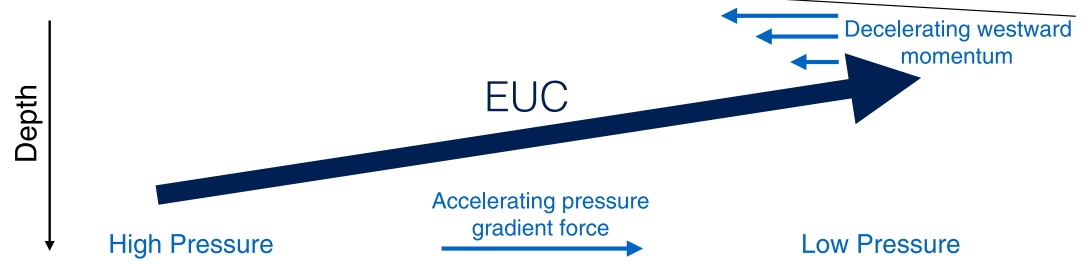

FIG. 3. Schematic of the equatorial Pacific showing the dominant terms driving the EUC and the hypothesized response of the EUC to a weakening equatorial zonal wind stress associated with a weakening Walker circulation. SSH is the sea surface height gradient. 
equatorial currents, in which a distinct separation of the contribution by local versus remote forcing has been shown to determine the climatology of the EUC (Yu et al. 1997). If this process also influences SST in the eastern equatorial Pacific, then the trends in Fig. 1c may be dynamically consistent.

Herein we seek to characterize the relationship between weakening equatorial zonal wind stress and EUC strength and then quantify the associated impact on SSTs in the eastern equatorial Pacific. The analyses will predominantly utilize the same ocean reanalysis as Drenkard and Karnauskas [2014; Simple Ocean Data Assimilation (SODA); Carton and Giese 2008], as it is the only ocean reanalysis that covers the entirety of the twentieth century and it has been shown to accurately reproduce independent zonal velocity observations at time scales from seasonal to decadal and longer trends (Drenkard and Karnauskas 2014). The consistency of the atmosphere-ocean dynamics controlling EUC strength and its impact on SST in the ocean reanalysis is compared with observations and state-of-theart CGCMs from the Coupled Model Intercomparison Project phase 5 (CMIP5). The latter development is important because it has been shown that twentiethcentury SST gradient trends in CMIP5 CGCMs are in opposition to those in observational datasets (Coats and Karnauskas 2017).

\section{Data}

The observational datasets used in this study include a reconstruction of SST based on bias-corrected observations that are interpolated onto an even grid (HadISST; Rayner et al. 2003), and bias-corrected station observations of SLP at Tahiti and Darwin (from the NOAA CPC and can be accessed at http://www.cpc. ncep.noaa.gov/data/indices/). The SST gradient is defined as the difference in average SSTs between $2^{\circ} \mathrm{N}-$ $2^{\circ} \mathrm{S}, 117^{\circ}-173^{\circ} \mathrm{E}$ and $2^{\circ} \mathrm{N}-2^{\circ} \mathrm{S}, 205^{\circ}-275^{\circ} \mathrm{E}$, and the SLP gradient, a metric of Walker circulation strength, is the difference in SLP between Tahiti and Darwin.

In situ observations include acoustic Doppler current profiler (ADCP; over the period 1985-2006) and fixeddepth current measurements, as well as wind data (both over the period 1985-2010) from the Tropical Atmosphere Ocean project (TAO) array (from the TAO Project Office of the Pacific Marine Environmental Laboratory, can be accessed at http://www.pmel.noaa. gov/tao/). Wind stress is calculated from the TAO array wind data using a bulk formula with a wind drag coefficient of 0.0013 , air density of $1.22 \mathrm{~kg} \mathrm{~m}^{-3}$, and a correction of 1.13 to go from the measurement height (4 m) to $10 \mathrm{~m}$ (using the wind power law; Hsu et al. 1994).
The ocean reanalysis used here is the SODA, in which an ocean general circulation model (OGCM) is forced by observed surface fluxes (heat, momentum, and freshwater) and constrained by ocean observations. SODA fields are the ensemble mean of eight model runs, each driven by a different realization of wind stress, heat, and freshwater fluxes from the NOAA Twentieth Century Reanalysis (20CR; Compo et al. 2011; Yang and Giese 2013). Herein, two versions of SODA are employed: version 2.2.4, which assimilates observations of SST and hydrographic observations, and version 2.2.6, which assimilates observations of SST only. Neither version of SODA assimilates velocity observations, thus the EUC dynamics analyzed herein are purely an emergent feature of the ocean model constrained by ocean observations and imposed surface fluxes. The spatial and temporal completeness of the gridded SODA product output allows for rigorous assessment of EUC dynamics over long periods of time, which would not be possible with the available in situ observations. (We use SODA, version 2.2.4, for all analyses but those in Fig. 10.)

All CGCM data is from the CMIP5 (Taylor et al. 2012) and the simulations employed herein are listed in Table 1 . Although only 14 CGCMs are analyzed, they produce a range of trends in the SST gradient over the analysis period (Table 1) and are thus a sufficient sample to support our results and interpretations. Five GCMs from phase 2 of the Co-ordinated Ocean-Ice Reference Experiments (CORE; Griffies et al. 2012) are additionally analyzed to better constrain potential model biases. These simulations are global ocean-sea ice GCMs run with a prescribed atmospheric state, with boundary fluxes computed via a common bulk formula (the period 1948-2007 is analyzed herein; Large and Yeager 2012). The MRI simulation from the CORE is compared to an MRI simulation with the same model setup that assimilates salinity and potential temperature data (Danabasoglu et al. 2014, 2016). All datasets are employed between 1900 and 2008 unless data is not available over the full analysis period (e.g., the TAO array observations, which only start in 1985 , and the CORE simulations, which only extend from 1948 to 2007).

\section{Methods}

\section{a. Lagrangian particle analysis}

The core of the EUC generally flows parallel to isotherms near the thermocline (Fig. 2), and thus subsurface zonal temperature advection directly by the EUC is small in many areas. However, when and where 
TABLE 1. SST gradient trend between 1900 and 2008 for the CMIP5 CGCMs used in Figs. 9 and 10. The trends in BNU-ESM and IPSLCM5A-LR are significant at the 95\% level against the stationary statistics of internal variability defined using surrogate SST gradient trends derived from a linear inverse model trained on each CGCM. The percentage rank of the actual SST gradient trend relative to surrogate SST gradient trends is also shown, ranking below the 5 th or above the 95 th percentile is considered significant at the $95 \%$ level (Coats and Karnauskas 2017). Expansions of the CGCM name acronyms can be found at https://www.ametsoc.org/index.cfm/ams/ publications/authors/journal-and-bams-authors/formatting-and-manuscript-components/list-of-acronyms-and-abbreviations/\#models.

\begin{tabular}{lcc}
\hline \hline \multicolumn{1}{c}{ CGCM } & 1900-2008 CE SST gradient trend $\left({ }^{\circ} \mathrm{C} \mathrm{century}^{-1}\right)$ & Percentage rank relative to linear inverse model trends $^{-1}$ \\
\hline BCC_CSM1.1 & -0.13 & $18 \%$ \\
BCC_CSM1.1(m) & 0.00 & $50 \%$ \\
BNU-ESM & -0.47 & $3 \%$ \\
CCSM4 & -0.14 & $32 \%$ \\
CESM1(BGC) & -0.09 & $38 \%$ \\
CESM1(CAM5) & -0.16 & $14 \%$ \\
CNRM-CM5 & -0.09 & $27 \%$ \\
FGOALS-g2 & 0.02 & $55 \%$ \\
GFDL CM3 & -0.11 & $24 \%$ \\
IPSL-CM5A-LR & 0.25 & $100 \%$ \\
IPSL-CM5A-MR & 0.05 & $73 \%$ \\
IPSL-CM5B-LR & -0.05 & $36 \%$ \\
NorESM1-M & 0.11 & $72 \%$ \\
NorESM1-ME & -0.16 & $24 \%$ \\
\hline
\end{tabular}

the EUC is associated with temperature advection, then a change in the strength of the EUC of sufficient magnitude will also change SST wherever water from the EUC reaches the mixed layer. To provide a qualitative assessment of this process (i.e., not characterizing actual SST changes, just the possibility that such changes should occur), a Lagrangian particle analysis was completed. To do so, the climatological monthly temperature and velocity fields (averaged at the two latitudinal grid points closest to the equator in the SODA, $0.25^{\circ} \mathrm{S}$ and $0.25^{\circ} \mathrm{N}$ ) are calculated over the period $1900-2008$ from monthly output of the SODA, version 2.2.4. Particles are initiated at the surface at each longitudinal grid point $\left(0.5^{\circ}\right.$ resolution $)$ within the box used to define the eastern component of the SST gradient (box 1 in Fig. 1a; $205^{\circ}-275^{\circ} \mathrm{E}$ ) on the 15 th day of each month. The particles are then propagated backward in time using the contemporaneous climatological monthly velocity fields and a 5-day time step (e.g., after 15 days, the particles initiated in December are advected by the November velocity fields). When the time step reaches 120 days or the particle is advected more than $1.5^{\circ}$ latitude off the equator (where the two-dimensional assumption underlying the Lagrangian particle analysis is no longer valid, i.e., the particles are no longer being advected by the equatorial velocity field), the particles trajectory is terminated.

To assess the extent to which a particle's trajectory is associated with temperature advection, we compare the slope of the particle's trajectory to the slope of the local isotherms. If the slope of the particle's trajectory is steeper (larger slope value) than the nearest local isotherm, then the particle at that location is associated with cold advection (and warm advection if it is less steep). We define a simple quantitative metric as the difference in the two slopes (oriented such that a negative value of the metric is indicative of cold advection). We compute the average of this metric annually and by month for all particles that pass through each equatorial (depth by longitude) grid point. Importantly, the Lagrangian particle analysis and associated metrics are calculated using monthly climatological fields. This will introduce quantitative errors into the analysis and the results should thus only be interpreted qualitatively.

\section{b. Mixed layer heat budget and momentum budget}

To provide a quantitative estimate of the SST change in the eastern equatorial Pacific associated with the EUC, a zonal momentum and mixed layer heat budget analysis is performed. Importantly, the budgets are calculated on monthly data and this may be one source of the residual terms analyzed in the following sections.

\section{1) Momentum Budget}

We use the arrangement of the zonal momentum equation following Drenkard and Karnauskas (2014; see also Brown et al. 2007; Qiao and Weisberg 1997):

$$
\begin{aligned}
\frac{\partial u}{\partial t}= & -u \frac{\partial u}{\partial x}-v \frac{\partial u}{\partial y}-w \frac{\partial u}{\partial z}-\frac{1}{\rho} \frac{\partial P}{\partial x}+2 \Omega v \sin \vartheta \\
& +A_{H} \nabla^{2} u+\frac{\partial}{\partial z}\left[A_{V}\left(\frac{\partial u}{\partial z}\right)\right],
\end{aligned}
$$

where, from left to right, the terms represent the time rate of change of zonal velocity, the zonal, meridional, and vertical nonlinear advective terms, the zonal pressure 
gradient force, and the Coriolis force followed by the horizontal and vertical friction terms. Density was calculated using the equation of state and salinity, temperature, and depth (Fofonoff and Millard 1983). The horizontal $\left(A_{H}\right)$ and vertical $\left(A_{V}\right)$ coefficients of eddy viscosity (in the last two terms) were not retained for SODA (Drenkard and Karnauskas 2014) and are thus estimated using a constant value of $1.5 \times 10^{-3} \mathrm{~m}^{2} \mathrm{~s}^{-1}$ for the horizontal coefficient, while the vertical coefficient was varied with depth: $4.5 \times 10^{-3} \mathrm{~m}^{2} \mathrm{~s}^{-1}$ above the thermocline, $1.5 \times 10^{-3} \mathrm{~m}^{2} \mathrm{~s}^{-1}$ below the thermocline, and a spline interpolation in between (Qiao and Weisberg 1997). As noted in Drenkard and Karnauskas (2014), these values remain largely unconstrained and represent the largest uncertainty in the momentum budget, likely contributing to a nontrivial mean residual (along with the use of monthly data). The momentum budget is calculated on isopycnals rather than depth (the native SODA grid) because the EUC shoals from west to east and thus zonal velocities associated with the EUC are not purely zonal (they also have a small vertical component). Nevertheless, the EUC closely follows isopycnals, making such an approach ideal for diagnosing the mechanisms underlying changes to EUC strength.

\section{2) Mixed LAYER HEAT BUdget}

The mixed layer temperature tendency equation is

$$
\begin{aligned}
\frac{\partial T}{\partial t}= & -u \frac{\partial T}{\partial x}-v \frac{\partial T}{\partial y}-w \frac{\partial T}{\partial z}+\text { res. } \\
& +\frac{Q_{\mathrm{SW}}-Q_{\mathrm{LW}}-Q_{\mathrm{SH}}-Q_{\mathrm{LH}}}{\rho C_{P} h},
\end{aligned}
$$

where, from left to right, the terms represent the time rate of change of mixed layer temperature, the zonal, meridional, and vertical temperature advection, a residual that represents mixing terms and errors related to temporal averaging, and net surface radiative fluxes and sensible and latent heat fluxes, with the density of seawater $\left(\rho, 1022 \mathrm{~kg} \mathrm{~m}^{-3}\right)$, specific heat capacity of seawater $\left(C_{p}, 3940 \mathrm{~J} \mathrm{~kg}^{-1} \mathrm{~K}^{-1}\right)$, and the depth of the mixed layer $h$. Mixed layer depth is defined here as the depth at which the slope of the vertical temperature gradient (calculated using a simple difference) is steeper than $-0.015^{\circ} \mathrm{Cm}^{-1}$ although results were confirmed to be insensitive to this choice or the use of a constant mixed layer depth (not shown). Net surface radiative flux and latent and sensible heat fluxes are taken from the NOAA Twentieth Century Reanalysis (Compo et al. 2011; Yang and Giese 2013), which is used as the atmospheric boundary conditions for the SODA. All subsequent derivatives including advection are calculated using central finite differencing.
For comparison to the Lagrangian particle analysis, the same rearrangement of the heat equation was used to calculate a gridpoint heat budget with isopycnals as the vertical coordinate for a two-dimensional cross section of the equatorial Pacific (averaged at the two grid points closest to the equator in the SODA, $0.25^{\circ} \mathrm{S}$ and $0.25^{\circ} \mathrm{N}$ ).

\section{c. Quantifying impact of EUC strengthening on eastern equatorial Pacific SSTs}

As noted in the introduction, the consequences of changes to EUC strength in the presence of a weakening Walker circulation and associated weakening of equatorial zonal wind stress is of particular interest for understanding twentieth-century trends in SST. There are, however, multiple mechanisms by which EUC strength can change (e.g., changes to the wind stress curl and hence western boundary currents feeding the EUC; Sen Gupta et al. 2012). In general, however, the EUC involves a balance between acceleration by the SSH gradient (or pressure gradient force) and deceleration by the downward transmission of westward momentum in the upper ocean (both of which arise from the climatological westward wind stress). Two mechanisms of EUC variability are thus defined, related to these two acceleration terms - the pressure gradient mode and the downwelling momentum mode (the deceleration by westward momentum). While the pressure gradient mode is the dominant driver of variability in the EUC, it is typically associated with a strengthening Walker circulation and thus is not of interest. However, isolating this mode allows for the identification of EUC variability solely related the downwelling momentum mode (see below).

The modes and their time histories between 1900 and 2008 are isolated using coupled singular value decomposition (SVD; Bretherton et al. 1992). Coupled SVD of along-isopycnal velocity and the pressure gradient force [from the momentum budget; section $3 \mathrm{~b}(1)$ ] are calculated for each month and the first principal component time series of along-isopycnal velocity is used to define the time history of the pressure gradient mode (using the domain $150^{\circ}$ to $270^{\circ} \mathrm{E}$ at the equator). To define the time history of the downwelling momentum mode, coupled SVD is calculated between zonal wind stress at the surface (using the domain $170^{\circ}$ to $260^{\circ} \mathrm{E}$ and $5^{\circ} \mathrm{N}$ to $5^{\circ} \mathrm{S}$ ) and the along-isopycnal velocity fields (using the same domain as above), and the first principal component time series of along-isopycnal velocity is used to define the time history of the downwelling momentum mode. Before calculating this SVD, however, zonal wind stress and along-isopycnal velocity are adjusted to remove the part that covaries with the pressure gradient mode. To do so, coupled SVD of these fields and the pressure gradient force (using the same 
domains as above) is calculated and the first mode, which corresponds to the pressure gradient mode (the pressure gradient mode as defined above and the principle component time series of this first mode correlate at an average of 0.98 across all months), is removed using standard SVD techniques in which the data is reconstructed without this first mode. The downwelling momentum mode can be identified using other terms from the zonal momentum budget. Nevertheless, it was found that multiple terms are important for transmitting changes in zonal wind stress to changes in upper-ocean westward momentum (principally vertical friction, and vertical and horizontal advection of zonal momentum). As noted above, coupled SVD is thus calculated using zonal wind stress and along-isopycnal velocity. The choice of domains used in the SVD calculations is largely based on trial and error, with the motivation of separating the two modes of EUC variability.

The downwelling momentum mode is the focus of the rest of the manuscript, as this is the mechanism by which Drenkard and Karnauskas (2014) suggest that the EUC strengthens during boreal summer in the SODA reanalysis-particularly in the eastern equatorial Pacific, where the EUC is relatively shallow and thus subject to subtle changes in wind stress magnitude. While the coupled SVD and associated modes are calculated for all months, a visual inspection of the downwelling momentum mode (i.e., the first mode of the coupled SVD of zonal wind stress and along isopycnal velocity) suggests that it is not characterized by weakening zonal wind stress and associated strengthening of the EUC during boreal winter and fall. This visual inspection further suggests that EUC variability associated with changes in downwelling westward momentum is weak during these seasons. The downwelling momentum mode is thus not shown or considered for the months of October-March.

All subsequent analyses consider the downwelling momentum mode over the entirety of April-September. However, observed twentieth-century trends in the Walker circulation only exhibit significant weakening in June, July, and August (Fig. 1c). Caution should thus be exercised when comparing these analyses and results to observed twentieth-century trends, and no attempt is made to provide a quantitative comparison.

A three-step process quantifies the impact of changes in the downwelling momentum mode on SSTs in the eastern equatorial Pacific:

1) Only years in the middle tercile (33\%) of detrended average SST anomalies in the eastern equatorial Pacific (box 1 in Fig. 1a) are isolated in order to prevent biasing results with strong ENSO events or other anomalous climate variability that is inconsistent with the magnitude of (and with some mechanisms that will be distinct from) the long-term changes of interest. For instance, during strong El Niño events, the EUC is known to weaken drastically and even disappear completely (e.g., Firing et al. 1983, a case that is inappropriate for characterizing the statistics of more subtle long-term changes).

2) The mixed layer heat budget terms are averaged over the bounds of the mixed layer and the eastern equatorial Pacific box in each month. For instance, the zonal temperature advection is the average zonal temperature advection for grid points above the base of the mixed layer at the east and west boundary and between the north and south boundaries of the eastern equatorial Pacific box, while the vertical temperature advection is the average vertical temperature advection for grid points at the base of the mixed layer and between the east, west, north, and south boundaries of the eastern equatorial Pacific box. The climatology is removed from the resulting time series to produce anomaly time series that are then detrended.

3) For 0- to 4-month lags, multiple (over all five lags, i.e., five predictors for each mixed layer heat budget term) and single (for each individual lag, a single predictor for each) linear regressions are calculated between the detrended downwelling momentum mode and the advection and residual terms. The reason for calculating two separate regressions (i.e., the single vs multiple linear regressions) is that only the total impact (i.e., over all five lags) and not the individual regression coefficients (e.g., those corresponding to a 1-month lag) are meaningful in multiple linear regression with correlated predictors, and the modes (the predictors) are highly correlated at all five lags. For example, a large change in the downwelling momentum mode in month 0 tends to correspond to a large change in that mode for months $1-4$. Lags of 0 to 4 months were analyzed in order to roughly capture the time scales of water crossing to the mixed layer in the eastern equatorial Pacific from the western extent of the EUC (the time scale comes from the Lagrangian particle analysis; section 3a). The inclusion of the residual from the mixed layer heat budget in these calculations is motivated by the need to capture mixing and other processes difficult to calculate and not resolved by the advective terms. Using the same methodology, multiple linear regressions are also calculated between the detrended downwelling momentum mode and detrended SSTs averaged over the eastern equatorial Pacific (box 1 in Fig. 1a).

Statistical significance is calculated using the Student's $t$ test for the individual linear regressions, with the 

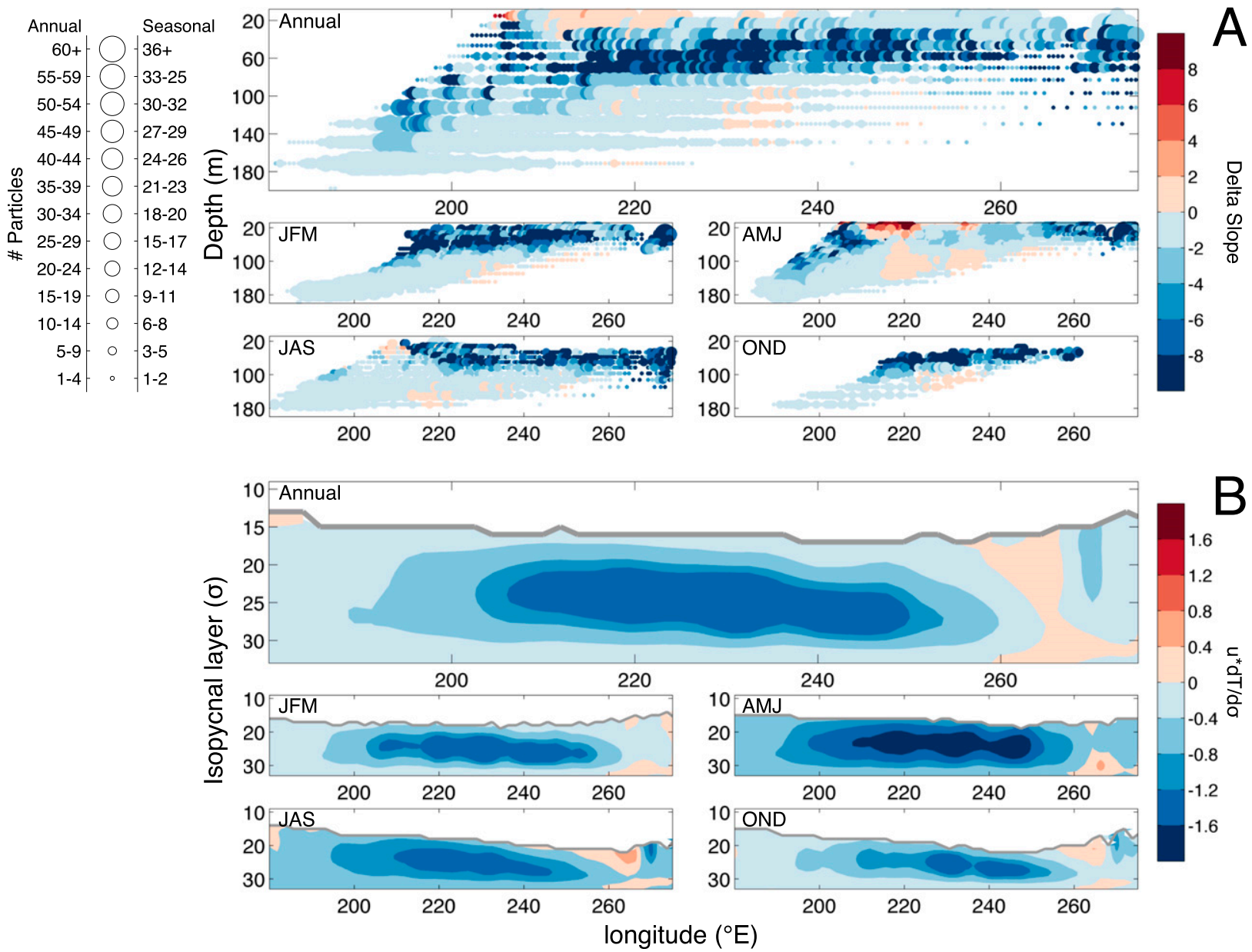

FIG. 4. (a) Using the annually and seasonally summed results of the Lagrangian particle analysis, the difference in the slope of the particle motion is compared to the local isotherm at each grid point. If the slope of the particle motion is steeper than that of the local isotherm it is associated with cold advection, and this difference metric is oriented such that negative values indicate cold advection (positive indicate warm advection; section 3a). The circle size indicates the number of particles that passed through each grid point. While all particles are seeded at the surface, the plotting of particle locations does not begin until the second time step (thus the lack of circles at the surface). (b) Along-isopycnal temperature advection from the annual and seasonal grid-point heat budgets calculated on isopycnals.

null hypothesis that the coefficients are equal to zero, and an $F$ test for the multiple linear regression model, with the null hypothesis of a constant (or "intercept") model.

\section{d. Comparison of observations, the ocean reanalysis, and CGCMs}

In section $4 \mathrm{c}$, the representation of coupled atmosphere-ocean dynamics related to EUC strength in the reanalysis is compared to CGCMs and observations (from the TAO array). Therein, EUC strength is defined as the maximum zonal velocity at each longitudinal grid point within $2^{\circ}$ latitude of the equator. The equatorial zonal wind stress (averaged within $2^{\circ}$ latitude of the equator), EUC depth, and strength are analyzed. Furthermore, a metric is defined that captures the expected sign and magnitude of a local change in equatorial zonal wind stress on local EUC strength. For each longitudinal grid point a correlation is calculated between standardized (monthly mean removed and divided by the monthly standard deviation) equatorial zonal wind stress and EUC strength for the months of April through September. The metric is oriented such that if the sign is positive it indicates that as the equatorial zonal wind stress weakens the EUC strengthens. For the observations, standardization utilizes the mean and standard deviation of equatorial zonal wind stress and EUC strength from the SODA reanalysis at the corresponding grid points. This is done because the observational record is too short to reliably estimate monthly standard deviations. Only years in the middle tercile $(33 \%)$ of detrended average SST anomalies in the eastern equatorial Pacific (box 1 in Fig. 1a) are included in the correlations to be consistent with other analyses. 

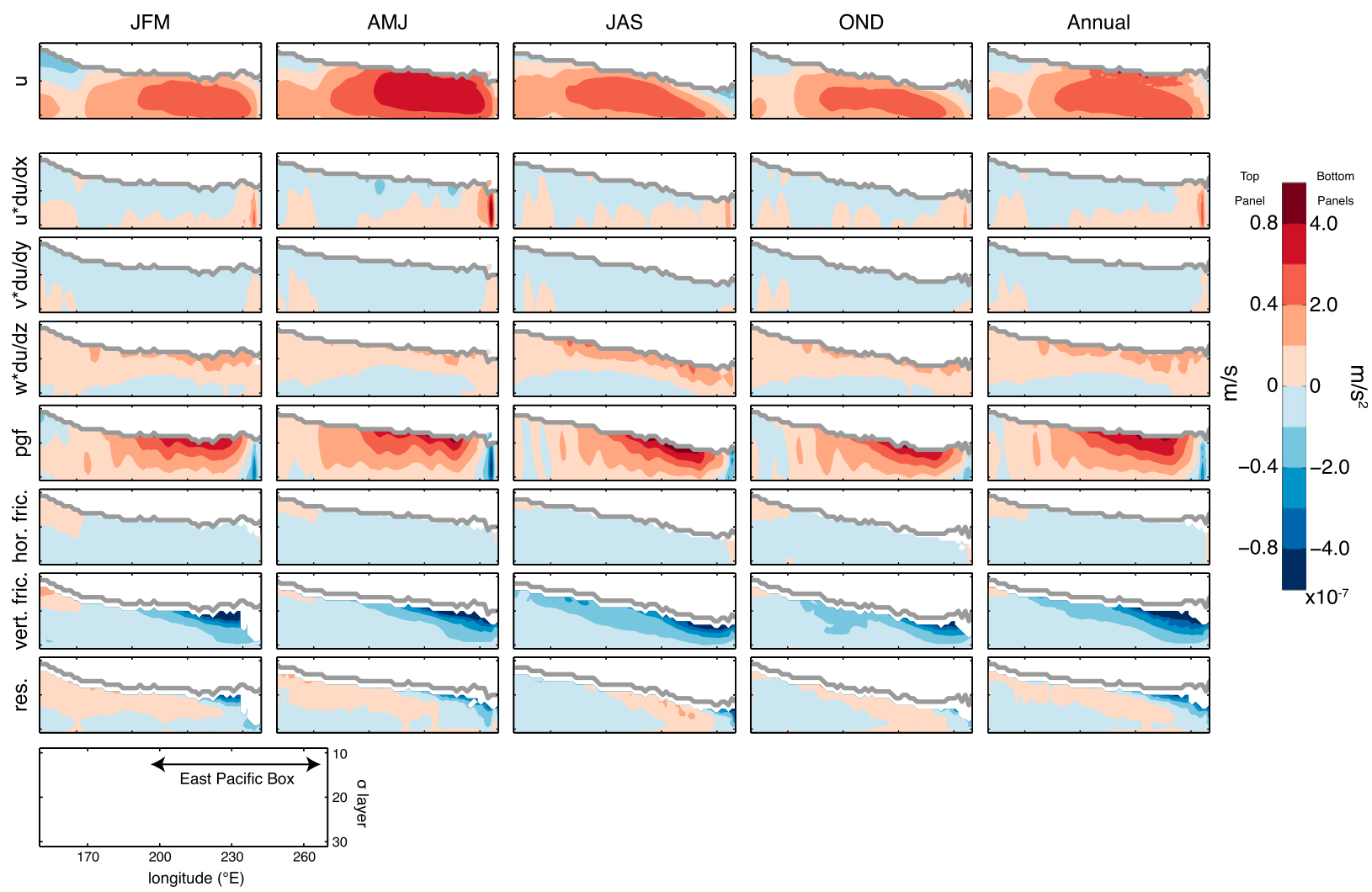

FIG. 5. Equatorial Pacific seasonal and annual climatology (averaged $2^{\circ} \mathrm{S}-2^{\circ} \mathrm{N}$ ) of along-isopycnal velocity and the momentum budget terms (section 3b). The lower-left panel shows the plotted domain (isopycnal layers 10 to 35 and $150^{\circ}$ to $270^{\circ} \mathrm{E}$ ).

\section{Results}

\section{a. Does the EUC cool the surface in the eastern equatorial Pacific?}

Figure 4a clearly demonstrates that outcropping water in the eastern equatorial Pacific is associated with the EUC. This is indicated by the fact that nearly all outcropping water passes through grid points at 150 - to $200-\mathrm{m}$ depth between $180^{\circ}$ and $205^{\circ} \mathrm{E}$ (Fig. $4 \mathrm{a} ; 85 \%$ of particles in the Lagrangian particle analysis), which is just upstream of the EUC core region. Nevertheless, there is considerable seasonality in these relationships, and Fig. 4a indicates that January-February-March (JFM), April-May-June (AMJ), and July-AugustSeptember (JAS) are the dominant months of EUC impact on the surface in the eastern equatorial Pacific. The short trajectory pathways in October-NovemberDecember (OND), as indicated by the large distance traveled by particles between seeding and the second time step and thus large vertical velocities (white space in the OND panel of Fig. 4a), suggest a dominant impact of wind stress divergence-driven equatorial upwelling in those seasons (i.e., a less direct impact for the EUC).
A comparison of the slope of the particle trajectory to that of the local isotherm at each grid point (as described in section 3a) suggests that particle trajectories in the EUC tend to cross isotherms (predominantly negative average slope difference values in Fig. 4a) and thus are associated with cold advection. Surfacing water that has undergone cold advection is expected to cool the mixed layer and SSTs, confirming that the EUC does cool the surface in the eastern equatorial Pacific.

These results are further supported by the equatorial gridpoint heat budget calculated on isopycnals in Fig. 4b. Because the EUC closely follows isopycnals, the along-isopycnal temperature advection is of particular interest for understanding the impact of the EUC on SSTs where those waters outcrop or reach the mixed layer. Along-isopycnal temperature advection is negative (cold advection) in the core EUC region in all seasons (and in the annual average).

\section{b. Quantifying the magnitude and mechanisms of EUC-related SST changes}

As expected from theory and observations, the climatological along-isopycnal velocity is primarily balanced by the pressure gradient force (acceleration) and 

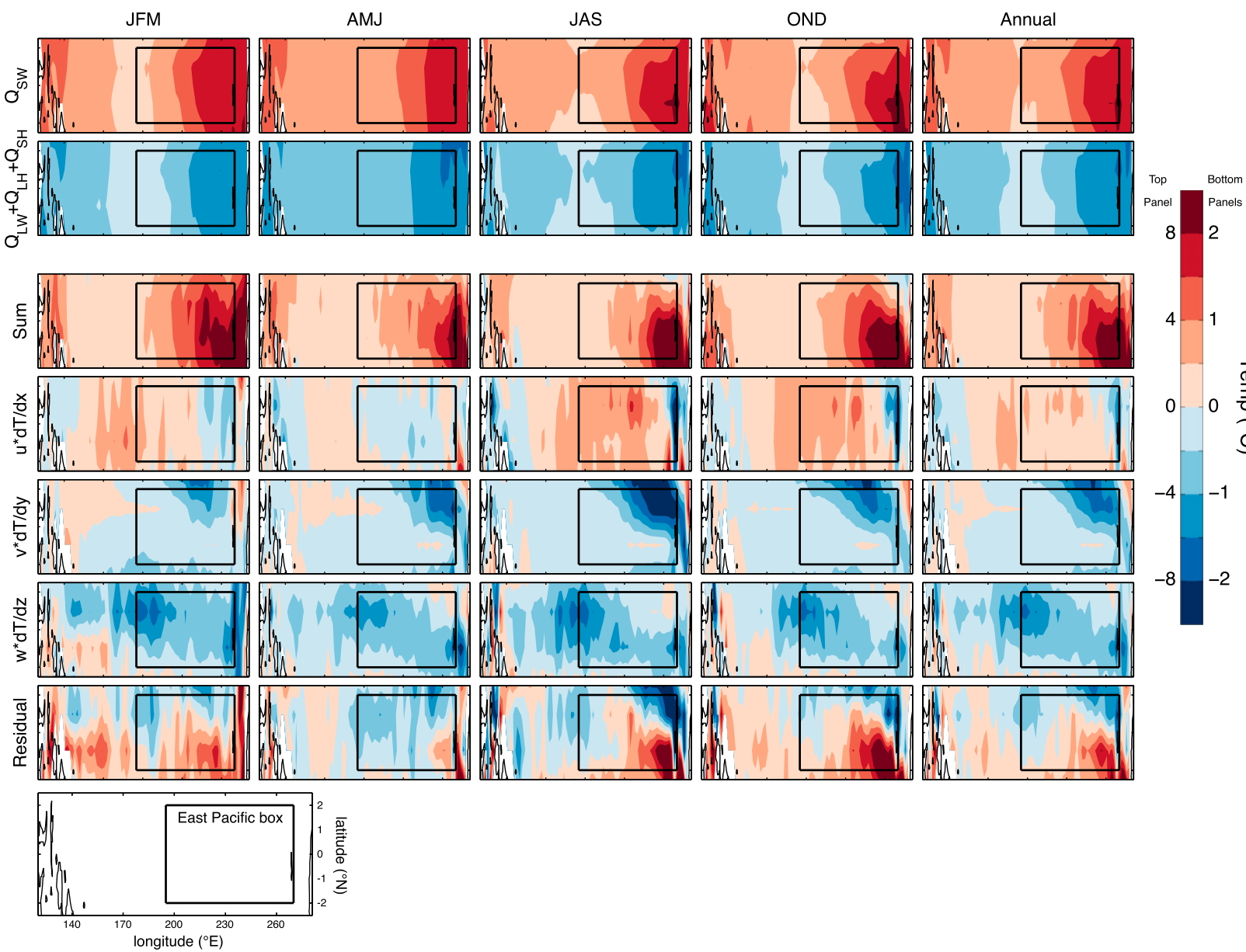

FIG. 6. Seasonal and annual climatology of the mixed layer heat budget in the equatorial Pacific (section $3 \mathrm{~b}$ ). Box 1 (EEP; $2^{\circ} \mathrm{N}-2^{\circ} \mathrm{S}, 205^{\circ}-$ $\left.275^{\circ} \mathrm{E}\right)$ of the SST gradient is denoted on each panel. The lower-left panel shows the plotted domain $\left(2.5^{\circ} \mathrm{N}-2.5^{\circ} \mathrm{S}, 100^{\circ}-300^{\circ} \mathrm{E}\right)$. "Sum" refers to the sum of the surface heat flux terms. All heat budget terms have been scaled so that they are in ${ }^{\circ} \mathrm{C}$.

vertical friction terms (deceleration; Fig. 5). Nevertheless, the nonlinear vertical advection is important in driving the seasonal shoaling and outcropping of the EUC during late boreal spring and summer. The climatological mixed layer heat budget is dominated by shortwave radiative heating and longwave sensible and latent cooling (Fig. 6). While these terms largely balance in the western equatorial Pacific, there is a large residual warming ("Sum") in the eastern equatorial Pacific that is balanced by the advective terms (resolved velocities advecting temperature gradients) and mixing (taken as the residual). In subsequent analyses, focus is restricted to the advective and mixing terms, as these are the terms most directly affected by the EUC (and ocean velocities in general).

Figure 7 shows the coupled SVD analysis outlined in section $3 \mathrm{c}$ by which the downwelling momentum mode is identified and isolated. The downwelling momentum mode represents a range of $59 \%-83 \%$ (mean $71 \%$ ) of the covariance between along-isopycnal velocity and surface zonal wind stress across the six months that the coupled SVDs were calculated (these latter covariances are the portion of covariance that remains after removing the pressure gradient force mode before calculating the SVD).

Positive phases of the downwelling momentum mode (strengthened EUC) are associated with mixed layer cooling in the eastern equatorial Pacific for nearly all months and lags via the zonal advective term (Table 2). These associations, however, are only significant in August (and June at zero lag). More fundamentally, the zonal advective term is only a small part of the total heat budget in the region (Fig. 6), so the SST change associated with this term is small. The meridional advective term is a larger part of the total heat budget and a positive phase of the downwelling momentum mode has either a weak relationship with the meridional advective term or is significantly associated with heating (June and July; Table 3). This heating is likely indicative of a slowdown of the subtropical cells as equatorial zonal 


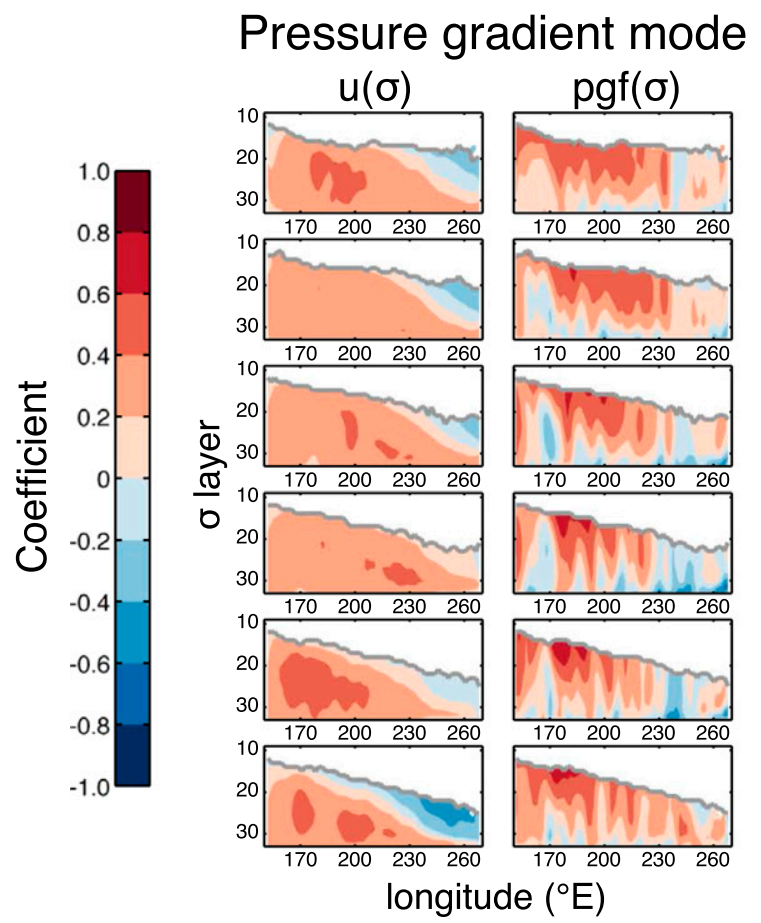

Downwelling momentum mode
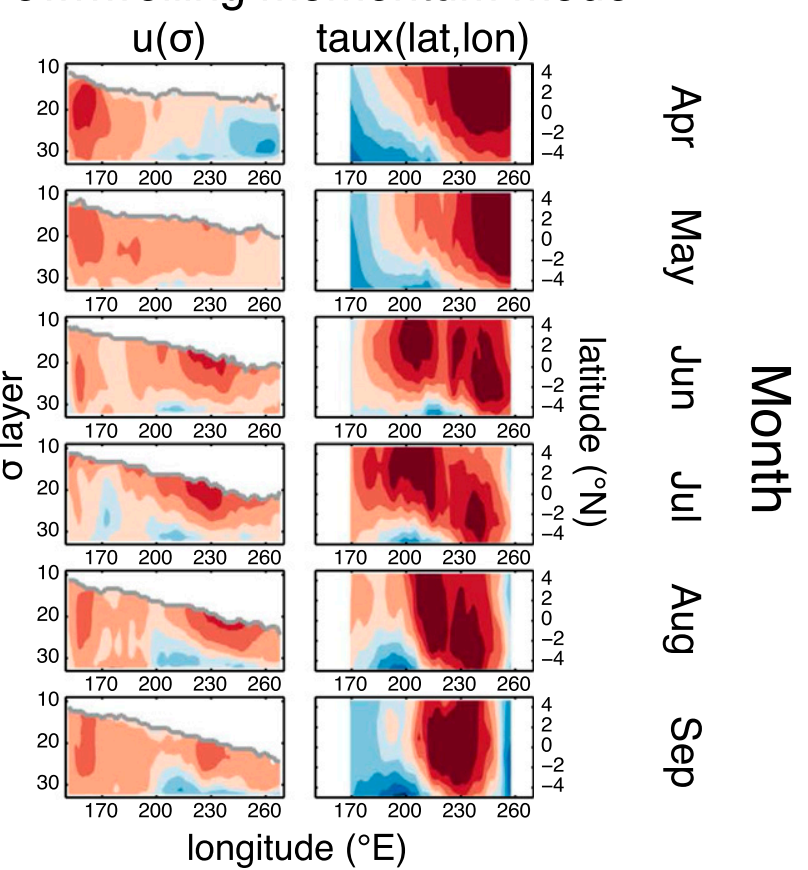

FIG. 7. (left) Coupled SVD of along-isopycnal velocity and the pressure gradient force (from the momentum budget in Fig. 5). The first and second columns are the patterns corresponding to the first mode of the SVD for along-isopycnal velocity and the pressure gradient force, respectively. (right) Coupled SVD of along-isopycnal velocity and zonal wind stress (downwelling momentum mode). As noted in section $3 \mathrm{c}$ the first mode of the coupled SVD of the pressure gradient force and zonal wind stress has been removed from the zonal wind stress before calculating the downwelling momentum mode. The first and second columns are the patterns corresponding to the first mode of the SVD for zonal velocity and zonal wind stress, respectively. The full methods are described in section 3c.

wind stress weakens and a subsequent decrease in the divergence of heat from the eastern equatorial Pacific (and not a direct impact of the EUC). Except for the shortest lags, a positive phase of the downwelling momentum mode is associated with cooling via vertical advection in June through November (though the association is only significant at long lags in September; Table 4). This is likely a direct impact of the EUC, as weakening equatorial zonal wind stress should actually decrease wind stress divergence and upwelling (the dominant source of vertical temperature advection). The EUC, however, is not a purely zonal current and thus will be associated with vertical velocities and vertical temperature advection. Finally, the downwelling momentum mode is significantly associated with cooling via the residual term at zero lag for May-September (Table 5). This appears to be the most important (i.e., large magnitude) impact of the downwelling momentum mode on the mixed layer heat budget.

We now turn to an estimate of the SST change in the eastern equatorial Pacific resulting from EUC strengthening associated with the downwelling momentum mode (Fig. 8). The results largely confirm what was shown for the single linear regressions (Tables 2-5). For instance, the zonal advective term is largely unimportant to the heat budget and the downwelling momentum mode is significantly associated with cooling via

TABLE 2. Regression coefficients $\left({ }^{\circ} \mathrm{C}\right.$ std $\left.^{-1}\right)$ between the standardized downwelling momentum mode and the zonal advection term from the mixed layer heat budget (Fig. 6). For each month the downwelling momentum mode is lagged from 0 to 4 months with respect to the zonal advection term. Results are only listed for months in which at least two lagged months are available to calculate the regression coefficients. Regression coefficients are calculated using years in the middle tercile of SSTs over box 1 (EEP; between 1900 and 2008). Regressions that are significant at the $90 \%$ level using a $t$ test are shown in bold text.

\begin{tabular}{lccccc}
\hline & \multicolumn{5}{c}{$u(d T / d z)$} \\
\cline { 2 - 6 } & Lag-0 & Lag-1 & Lag-2 & Lag-3 & Lag-4 \\
\hline May & $\mathbf{- 0 . 0 1}$ & 0 & & & \\
Jun & -0.01 & 0 & 0 & & \\
Jul & 0.01 & 0.01 & 0 & -0.01 & \\
Aug & -0.01 & -0.02 & $\mathbf{- 0 . 0 2}$ & $\mathbf{- 0 . 0 2}$ & $\mathbf{- 0 . 0 2}$ \\
Sep & 0 & 0 & -0.01 & -0.01 & -0.01 \\
Oct & & $\mathbf{0 . 0 1}$ & 0.01 & 0 & -0.01 \\
Nov & & & 0.01 & 0 & 0 \\
Dec & & & & 0 & 0 \\
\hline
\end{tabular}


TABLE 3. As in Table 2, but for the horizontal advection term.

\begin{tabular}{lccccc}
\hline \hline & \multicolumn{5}{c}{$v(d T / d z)$} \\
\cline { 2 - 6 } & Lag-0 & Lag-1 & Lag-2 & Lag-3 & Lag-4 \\
\hline May & 0.04 & 0.03 & & & \\
Jun & $\mathbf{0 . 1 1}$ & $\mathbf{0 . 0 9}$ & $\mathbf{0 . 0 6}$ & & \\
Jul & $\mathbf{0 . 1 4}$ & $\mathbf{0 . 1 5}$ & $\mathbf{0 . 1 3}$ & $\mathbf{0 . 1 1}$ & \\
Aug & 0.07 & 0.03 & 0.01 & 0.01 & $\mathbf{0 . 1 2}$ \\
Sep & 0.04 & 0.04 & 0.01 & 0.02 & 0.05 \\
Oct & & 0.04 & 0.03 & -0.01 & 0.01 \\
Nov & & & 0 & 0 & 0 \\
Dec & & & & 0.01 & 0.03 \\
\hline
\end{tabular}

the residual term in May-September. This cooling is partially compensated by heating from meridional temperature advection (significant from June through August). However, this compensation is not large enough to balance cooling associated with the residual term, leading to a significant cooling of SSTs in the eastern equatorial Pacific between May and October (with the exception of July). Together this suggests that weakening equatorial zonal wind stress (e.g., that associated with a weakening Walker circulation) can increase the SST gradient by cooling the eastern equatorial Pacific via the downwelling momentum mode. The magnitude of this cooling is particularly large in MayAugust when there is the largest discrepancy in observed Walker circulation and SST gradient trends (Fig. 1c).

\section{c. Coupled atmosphere-ocean dynamics controlling EUC strength in CGCMs and observations}

In the preceding analyses, the downwelling momentum mode is identified and characterized using an ocean reanalysis. It is thus critical to validate the presence and importance of this mode in the real world using observations. Likewise, it is critical to validate the presence and importance of this mode in CGCMs, specifically with an eye toward whether CGCMs simulate the coupled atmosphere-ocean dynamics necessary to reproduce the real-world response of the equatorial Pacific to anthropogenic forcing.

There is relatively good agreement in the average strength (maximum zonal velocity) and depth of the EUC, as well as in the average magnitude of equatorial zonal wind stress in observations, CGCMs, and the ocean reanalysis (Fig. 9). However, there are systematic differences, with the CGCMs and the ocean reanalysis underestimating average equatorial zonal wind stress and EUC strength near the date line and the ocean reanalysis overestimating both in the eastern equatorial Pacific. There is also relatively good agreement in the magnitude of EUC strength and equatorial zonal wind stress variability between the ocean reanalysis and CGCMs (not shown), although there is greater EUC
TABLE 4. As in Table 2, but for the vertical advection term.

\begin{tabular}{llrrrr}
\hline \hline & \multicolumn{5}{c}{$w(d T / d z)$} \\
\cline { 2 - 6 } & Lag-0 & Lag-1 & Lag-2 & Lag-3 & Lag-4 \\
\hline May & 0.06 & 0.05 & & & \\
Jun & 0 & -0.03 & -0.03 & & \\
Jul & 0.02 & -0.02 & -0.02 & 0.01 & \\
Aug & 0.02 & -0.06 & $\mathbf{- 0 . 0 7}$ & $\mathbf{- 0 . 0 7}$ & -0.05 \\
Sep & $\mathbf{0 . 0 5}$ & $\mathbf{0 . 0 7}$ & 0.04 & -0.01 & -0.02 \\
Oct & & -0.03 & -0.04 & 0.01 & -0.01 \\
Nov & & & -0.03 & -0.04 & 0.01 \\
Dec & & & & -0.04 & -0.05 \\
\hline
\end{tabular}

strength variability in the ocean reanalysis. Both appear to underestimate the magnitude of variability relative to moored observations but this comparison is complicated by the limited length of the TAO mooring record. Overall, biases in the character of the EUC and equatorial zonal wind stress are not sufficiently large in magnitude to suggest, a priori, that there must be biases in their relationships to one another.

The response of local EUC strength to variations in the overlying equatorial zonal wind stress is consistent in observations, CGCMs, and the ocean reanalysis west of $210^{\circ} \mathrm{E}$, with a strengthening of the EUC as the magnitude of (easterly) wind stress strengthens. In stark contrast, east of $210^{\circ} \mathrm{E}$, where the EUC has shoaled and interacts more directly with the decelerating upperocean westward momentum, there appears to be a serious discrepancy in the response of EUC strength to variations in equatorial zonal wind stress. In the ocean reanalysis and observations the EUC strengthens as the equatorial zonal wind stress weakens, suggesting a dominant role for the downwelling momentum mode. In CGCMs, the EUC still weakens in the eastern equatorial Pacific when the local equatorial zonal wind stress weakens, despite the EUC realistically shoaling from west to east.

Why do the CGCMs not correctly simulate a downwelling momentum mode associated with EUC strengthening? This bias is related, in part, to the coupling of the atmosphere and ocean in CGCMs, as ocean-sea ice GCMs run with a prescribed atmospheric state better represent the relationship between changes in equatorial zonal wind stress and EUC strength (Fig. 10). The improvement in uncoupled OGCMs relative to CGCMs, however, is small and limited to the far eastern equatorial Pacific. Errors in the thermohaline structure of the eastern equatorial Pacific appear to be more important, since data assimilation greatly improves this bias (Fig. 10). However, even when assimilating data, GCMs (and the ocean reanalyses) do not perfectly reproduce the observed equatorial zonal wind stress-EUC strength relationship (although the observations are 
TABLE 5. As in Table 2, but for the residual term.

\begin{tabular}{lrrrrr}
\hline \hline & \multicolumn{5}{c}{ Residual } \\
\cline { 2 - 6 } & Lag-0 & Lag-1 & Lag-2 & Lag-3 & Lag-4 \\
\hline May & $\mathbf{- 0 . 1 8}$ & $\mathbf{- 0 . 3 3}$ & & & \\
Jun & $\mathbf{- 0 . 1 9}$ & -0.13 & $\mathbf{- 0 . 1 9}$ & & \\
Jul & $\mathbf{- 0 . 2 2}$ & -0.16 & -0.15 & $\mathbf{- 0 . 2 5}$ & \\
Aug & $\mathbf{- 0 . 2 6}$ & 0.07 & 0.14 & 0.14 & $\mathbf{- 0 . 1 8}$ \\
Sep & $\mathbf{- 0 . 2 2}$ & $\mathbf{- 0 . 2 6}$ & -0.07 & 0.05 & 0.02 \\
Oct & & -0.12 & -0.12 & -0.08 & -0.01 \\
Nov & & & -0.04 & 0 & 0.03 \\
Dec & & & & $-\mathbf{0 . 1 3}$ & -0.15 \\
\hline
\end{tabular}

clearly limited in longitudinal resolution because of the spacing of TAO moorings). For instance, this relationship is overestimated in the MRI simulation with data assimilation, while it may be underestimated in the SODA reanalyses. Additionally, the assimilation of hydrographic observations in SODA 2.2.4 (relative to just SSTs in SODA 2.2.6) leads to differences between the two SODA reanalyses, with a decrease in the magnitude of the relationship around $220^{\circ} \mathrm{E}$ in SODA 2.2.4 and a qualitatively better representation overall. Most importantly, the CMIP5 multimodel ensemble falls outside the range of observations and data assimilation products in terms of the EUC response to zonal wind variations in the eastern equatorial Pacific.

\section{Discussion and conclusions}

An ocean reanalysis is used to characterize a mechanism of EUC strengthening that is related to weakening equatorial zonal wind stress (smaller in magnitude than is typically associated with ENSO events). In this mechanism, associated decreases in upper-ocean westward momentum cause an acceleration of the EUC. This acceleration dominates over the deceleration caused by a decreasing SSH gradient, and associated pressure gradient force, causing a strengthening of the EUC that can then cool the eastern equatorial Pacific, with relevance to the SST gradient. Importantly, the identification of this cooling can help to reconcile the late boreal spring and summer weakening Walker circulation and increasing SST gradient trends in observations (Fig. 1c). The weakening Walker circulation can actually drive an increasing SST gradient by strengthening the EUC, at least to the extent that shorter time-scale dynamics and relationships also operate on longer time scales.

The major conclusions of this study are as follows:

- The EUC cools SSTs in the eastern equatorial Pacific.

- The weakening equatorial zonal wind stress (e.g., that associated with a weakening Walker circulation) can increase the SST gradient by cooling the eastern equa-
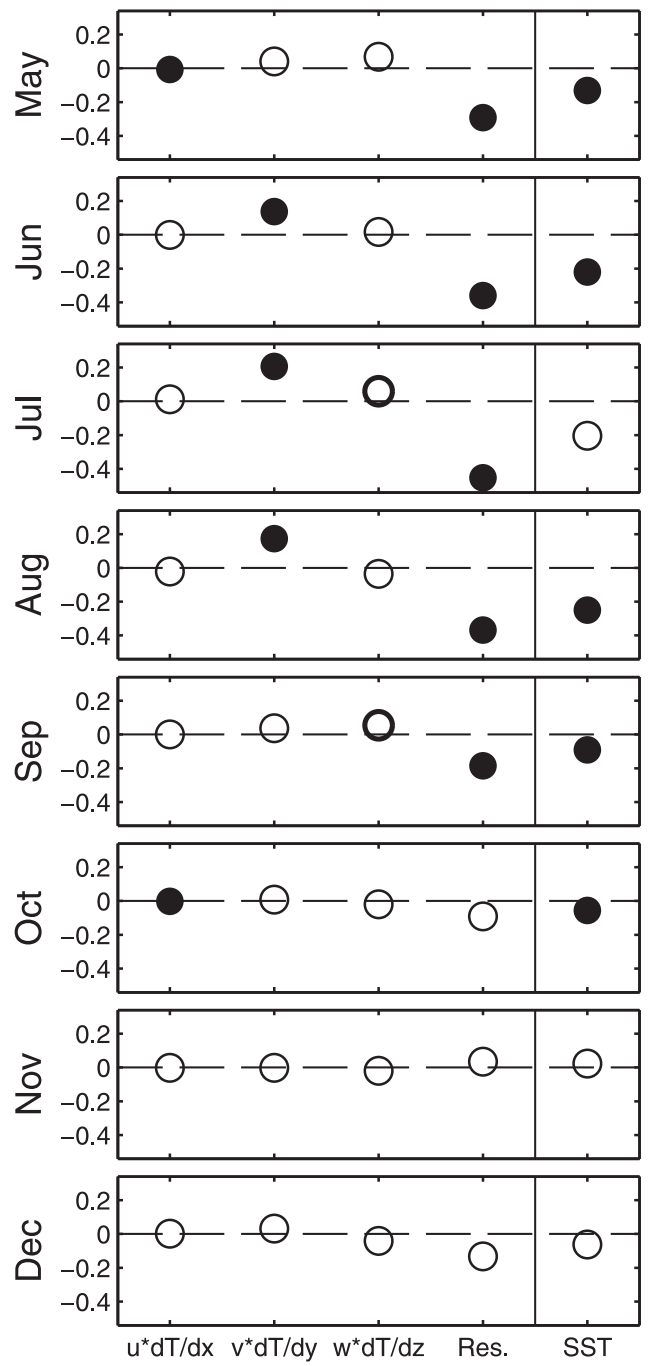

FIG. 8. Results of the analysis outlined in section $3 \mathrm{c}$. Total impact (over lags 0 to 4 months; the sum of the multiple linear regression outlined in section 3c) for each mixed layer heat budget term. To the right of the solid line is the sum over lags 0 to 4 months for the multiple linear regression using SSTs averaged over the EEP (box 1). Filled circles are significant at the $95 \%$ level and thick circles are significant at the $90 \%$ level.

torial Pacific via the downwelling momentum mode. The magnitude of this cooling is particularly large in boreal spring and summer when there is the largest discrepancy in observed Walker circulation and SST gradient trends.

- There is a bias in the response of EUC strength to variations in equatorial zonal wind stress in CGCMs. This bias is related, in part, to biases in the thermohaline structure of the eastern equatorial Pacific.

The analyses herein have relied on a single ocean reanalysis. Nevertheless, the coupled atmosphere-ocean dynamics have theoretical and conceptual precedence 

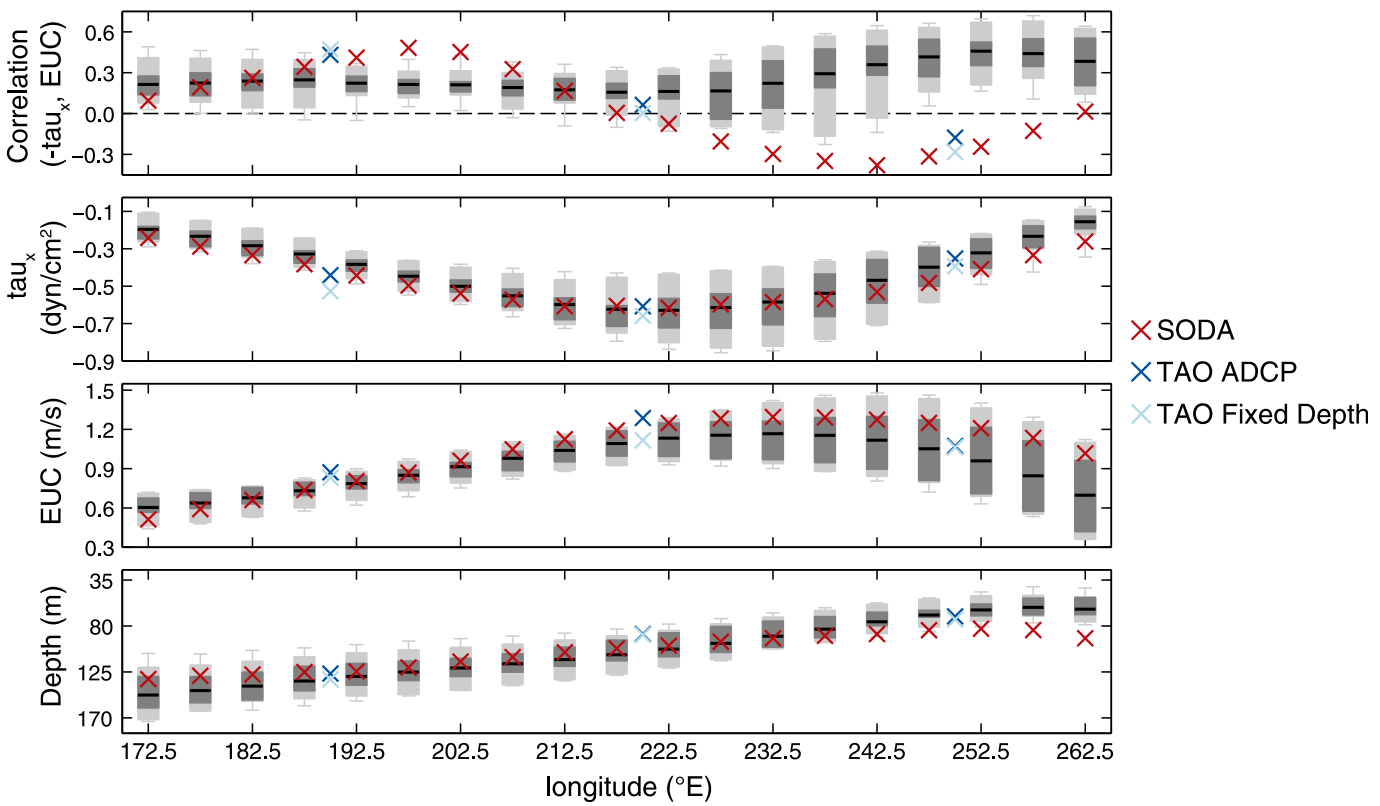

FIG. 9. (top) Relationship between changes in equatorial zonal wind stress (averaged $2^{\circ} \mathrm{S}$ to $2^{\circ} \mathrm{N}$ ) and maximum zonal velocity (EUC strength) at each longitude for a 14-member set of the CMIP5 historical simulations (Table 1), the ocean reanalysis (SODA, version 2.2.4; Carton and Giese 2008), and observations (TAO). This is defined as the correlation between monthly, standardized equatorial zonal wind stress and standardized EUC strength at each longitude for the months of April to September. Only years in the middle tercile (33\%) of detrended average SST anomalies in the EEP (box 1 in Fig. 1a) are included in the correlations to be consistent with other analyses. (bottom) Average equatorial zonal wind stress, EUC strength, and depth of the EUC at each longitude for the same datasets. In all panels the gray bars are the range of the values for the CMIP5 simulations. The whiskers are the full range, light gray is the 5 th to 95 th percentiles, dark gray is the 25 th to 75 th percentiles, and the black line is the median.

and are validated against observations. CGCMs, however, are unable to simulate the mechanism by which a weakening Walker circulation strengthens the EUC and this may be one reason that SST gradient trends in CGCMs are largely in opposition to those in observational datasets [Coats and Karnauskas (2017), although there are observational uncertainties, e.g., Deser et al. (2010); Thompson et al. (2008); Kennedy (2014)]. It is thus critical to validate that CGCMs can realistically simulate the response of the climate system to anthropogenic forcing in key regions of air-sea interaction such as the eastern equatorial Pacific. The results presented

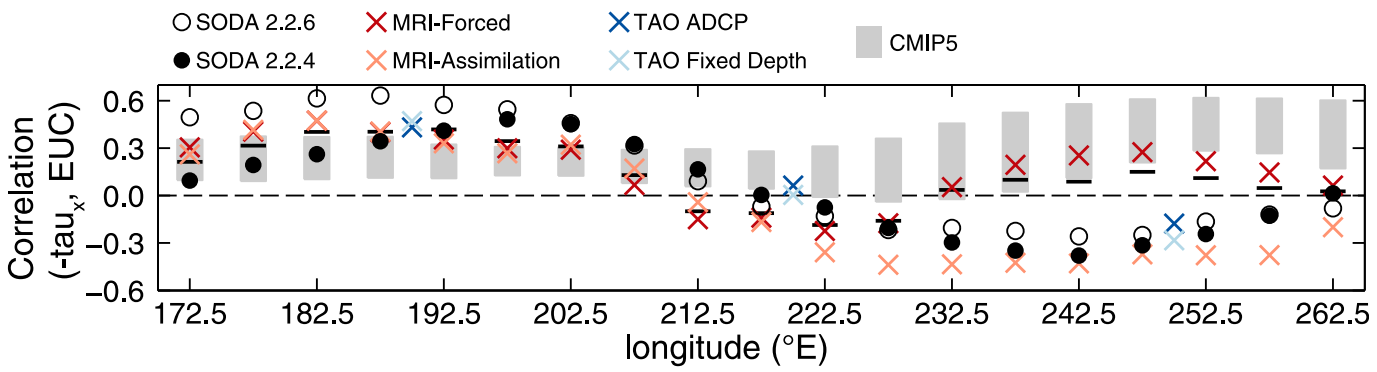

FIG. 10. Same metric as the top panel of Fig. 9. The black line is the mean of this metric for five GCMs from phase 2 of the CORE (Griffies et al. 2012). These simulations are global ocean-sea ice GCMs run with a prescribed atmospheric state, with boundary fluxes computed via the same bulk formulae (the common period 1948-2007 is analyzed herein; Large and Yeager 2009). The gray shaded regions are the range in the mean of this metric for all subsets of five CGCMs from the CMIP5 historical simulations (14 total simulations; 2002 total combinations). The MRI simulation from the CORE is additionally compared to an MRI simulation with the same setup that assimilates salinity and potential temperature data (Danabasoglu et al. 2014, 2016). For reference, the same values from observations (TAO) and SODA reanalyses that assimilate just surface observations (SODA, version 2.2.6) and both surface and depth observations (SODA, version 2.2.4, as shown in all other plots) are also plotted. 
herein suggest that this will require process studies targeting the transmission of small variations in wind stress to the subsurface to compare to the parameterization of these processes in CGCMs. Given the equatorial Pacific's critical role in the global climate system, this endeavor will help to improve climate change projections and thus allow society to better plan for and adapt to climate change.

Acknowledgments. We acknowledge the World Climate Research Programme's Working Group on Coupled Modelling, which is responsible for CMIP, and we thank the climate modeling groups for producing and making available their model output. For CMIP, the U.S. Department of Energy's Program for Climate Model Diagnosis and Intercomparison provides coordinating support and led development of software infrastructure in partnership with the Global Organization for Earth System Science Portal. We further thank Haibo Liu and Naomi Henderson for their considerable computational support, and Drs. Peter Molnar, Gokhan Danabasoglu, and Richard Seager for helpful discussions and comments on earlier versions of the manuscript.

\section{REFERENCES}

Bjerknes, J., 1966: A possible response of the atmospheric Hadley circulation to equatorial anomalies of ocean temperature. Tellus, 18 (4), 820-829, https://doi.org/10.3402/tellusa.v18i4.9712.

_ 1969: Atmospheric teleconnections from the equatorial $\mathrm{Pa}$ cific. Mon. Wea. Rev., 97, 163-172, https://doi.org/10.1175/ 1520-0493(1969)097<0163:ATFTEP > 2.3.CO;2.

Bretherton, C. S., C. Smith, and J. M. Wallace, 1992: An intercomparison of methods for finding coupled patterns in climate data. J. Climate, 5, 541-560, https://doi.org/10.1175/ 1520-0442(1992)005<0541:AIOMFF >2.0.CO;2.

Brown, J. N., J. S. Godfrey, and R. Fiedler, 2007: A zonal momentum balance on density layers for the central and eastern equatorial Pacific. J. Phys. Oceanogr., 37, 1939-1955, https:// doi.org/10.1175/JPO3090.1.

Cane, M. A., A. C. Clement, A. Kaplan, Y. Kushnir, D. Pozdnyakov, R. Seager, S. E. Zebiak, and R. Murtugudde, 1997: Twentiethcentury sea surface temperature trends. Science, 275, 957-960, https://doi.org/10.1126/science.275.5302.957.

Carton, J. A., and B. S. Giese, 2008: A reanalysis of ocean climate using Simple Ocean Data Assimilation (SODA). Mon. Wea. Rev., 136, 2999-3017, https://doi.org/10.1175/ 2007MWR1978.1.

Clement, A. C., R. Seager, M. A. Cane, and S. E. Zebiak, 1996: An ocean dynamical thermostat. J. Climate, 9, 2190-2196, https:// doi.org/10.1175/1520-0442(1996)009<2190:AODT>2.0.CO;2.

Coats, S., and K. B. Karnauskas, 2017: Are simulated and observed twentieth century tropical Pacific sea surface temperature trends significant relative to internal variability? $G e$ ophys. Res. Lett., 44, 9928-9937, https://doi.org/10.1002/ 2017GL074622.

Compo, G. P., and Coauthors, 2011: The Twentieth Century Reanalysis Project. Quart. J. Roy. Meteor. Soc., 137, 1-28, https:// doi.org/10.1002/qj.776.
Danabasoglu, G., and Coauthors, 2014: North Atlantic simulations in Coordinated Ocean-Ice Reference Experiments phase II (CORE-II). Part I: Mean states. Ocean Modell., 73, 76-107, https://doi.org/10.1016/j.ocemod.2013.10.005.

_- , and Coauthors, 2016: North Atlantic simulations in Coordinated Ocean-Ice Reference Experiments phase II (CORE-II). Part II: Inter-annual to decadal variability. Ocean Modell., 97, 65-90, https://doi.org/10.1016/ j.ocemod.2015.11.007.

Deser, C., A. S. Phillips, and M. A. Alexander, 2010: Twentieth century tropical sea surface temperature trends revisited. Geophys. Res. Lett., 37, L10701, https://doi.org/10.1029/2010GL043321.

Drenkard, E. J., and K. B. Karnauskas, 2014: Strengthening of the Pacific Equatorial Undercurrent in the SODA reanalysis: Mechanisms, ocean dynamics, and implications. J. Climate, 27, 2405-2416, https://doi.org/10.1175/JCLI-D-13-00359.1.

Fedorov, A. V., and G. F. Philander, 2000: Is El Niño changing? Science, 288, 1997-2002, https://doi.org/10.1126/ science.288.5473.1997.

Firing, E., R. Lukas, J. Sadler, and K. Wyrtki, 1983: Equatorial Undercurrent disappears during 1982-1983 El Niño. Science, 222, 1121-1123, https://doi.org/10.1126/science.222.4628.1121.

Fofonoff, N. P., and R. C. Millard Jr., 1983: Algorithms for the computation of fundamental properties of seawater. Unesco Tech. Papers in Marine Science 44, 54 pp.

Giese, B. S., and S. Ray, 2011: El Niño variability in Simple Ocean Data Assimilation (SODA), 1871-2008. J. Geophys. Res., 116, C02024, https://doi.org/10.1029/2010JC006695.

Griffies, S. M., M. Winton, B. Samuels, G. Danabasoglu, S. Yeager, S. Marsland, H. Drange, and M. Bentsen, 2012: Datasets and protocol for the CLIVAR WGOMD Coordinated Ocean-Sea Ice Reference Experiments (COREs). WCRP Rep., 21 pp.

Held, I. M., and B. J. Soden, 2006: Robust responses of the hydrological cycle to global warming. J. Climate, 19, 5686-5699, https://doi.org/10.1175/JCLI3990.1.

Hsu, S. A., E. A. Meindl, and D. B. Gilhousen, 1994: Determining the power-law wind-profile exponent under near-neutral stability conditions at sea. J. Appl. Meteor., 33, 757-765, https:// doi.org/10.1175/1520-0450(1994)033<0757:DTPLWP>2.0.CO;2.

Johnson, G. C., B. M. Sloyan, W. S. Kessler, and K. E. McTaggart, 2002: Direct measurements of upper ocean currents and water properties across the tropical Pacific during the 1990s. Prog. Oceanogr., 52, 31-61, https://doi.org/10.1016/ S0079-6611(02)00021-6.

Jones, J. H., 1969: Surfacing of Pacific Equatorial Undercurrent: Direct observation. Science, 163, 1449-1450, https://doi.org/ 10.1126/science.163.3874.1449.

Karnauskas, K. B., R. Seager, A. Kaplan, Y. Kushnir, and M. A. Cane, 2009: Observed strengthening of the zonal sea surface temperature gradient across the equatorial Pacific Ocean. J. Climate, 22, 4316-4321, https://doi.org/10.1175/ 2009JCLI2936.1.

Kennedy, J.-J., 2014: A review of uncertainty in in situ measurements and data sets of sea surface temperature. Rev. Geophys., 52, 1-32, https://doi.org/10.1002/2013RG000434.

Kociuba, G., and S. B. Power, 2015: Inability of CMIP5 models to simulate recent strengthening of the Walker circulation: Implications for projections. J. Climate, 28, 20-35, https://doi.org/ 10.1175/JCLI-D-13-00752.1.

Kosaka, Y., and S.-P. Xie, 2013: Recent global-warming hiatus tied to equatorial Pacific surface cooling. Nature, 501, 403-407, https://doi.org/10.1038/nature12534. 
Large, W. G., and S. G. Yeager, 2009: The global climatology of an interannually varying air-sea flux data set. Climate Dyn., 33, 341-364, https://doi.org/10.1007/s00382-008-0441-3.

_ global sea surface temperature and air-sea heat fluxes (19842006). J. Climate, 25, 6123-6135, https://doi.org/10.1175/ JCLI-D-11-00148.1.

L'Heureux, M. L., D. C. Collins, and Z.-Z. Hu, 2013: Linear trends in sea surface temperature of the tropical Pacific Ocean and implications for the El Niño-Southern Oscillation. Climate Dyn., 40, 1223-1236, https://doi.org/10.1007/s00382-012-1331-2.

Power, S. B., and G. Kociuba, 2011: The impact of global warming on the Southern Oscillation index. Climate Dyn., 37, 17451754, https://doi.org/10.1007/s00382-010-0951-7.

Qiao, L., and R. H. Weisberg, 1997: The zonal momentum balance of the Equatorial Undercurrent in the central Pacific. J. Phys. Oceanogr., 27, 1094-1119, https://doi.org/10.1175/ 1520-0485(1997)027<1094:TZMBOT>2.0.CO;2.

Rayner, N. A., D. E. Parker, E. B. Horton, C. K. Folland, L. V. Alexander, D. P. Rowell, E. C. Kent, and A. Kaplan, 2003: Global analyses of sea surface temperature, sea ice, and night marine air temperature since the late nineteenth century. J. Geophys. Res., 108, 4407, https://doi.org/10.1029/2002JD002670.

Sandeep, S., F. Stordal, P. D. Sardeshmukh, and G. P. Compo, 2014: Pacific Walker circulation variability in coupled and uncoupled climate models. Climate Dyn., 43, 103-117, https:// doi.org/10.1007/s00382-014-2135-3.

Sarachik, E. S., and M. A. Cane, 2010: The El Niño-Southern Oscillation Phenomenon. Cambridge University Press, 369 pp.

Schubert, S. D., M. J. Suarez, P. J. Pegion, R. D. Koster, and J. T. Bacmeister, 2004: On the cause of the 1930s Dust Bowl. Science, 303, 1855-1859, https://doi.org/10.1126/science.1095048.

Seager, R., 2015: Decadal hydroclimate variability across the Americas. Climate Change: Multidecadal and Beyond, C.-P. Chang et al., Eds., World Scientific Series on Asia-Pacific Weather and Climate, Vol. 6, World Scientific, 235-254.

_- and R. Murtugudde, 1997: Ocean dynamics, thermocline adjustment, and regulation of tropical SST. J. Climate, $\mathbf{1 0}$, 521-534, https://doi.org/10.1175/1520-0442(1997)010<0521: ODTAAR $>2.0 . \mathrm{CO} ; 2$.

— , and G. A. Vecchi, 2010: Greenhouse warming and the 21st century hydroclimate of southwestern North America. Proc. Natl. Acad. Sci. USA, 107, 21 277-21282, https://doi.org/ 10.1073/pnas.0910856107.

Sen Gupta, A., A. Ganachaud, S. McGregor, J. N. Brown, and L. Muir, 2012: Drivers of the projected changes to the Pacific Ocean equatorial circulation. Geophys. Res. Lett., 39, L09605, https://doi.org/10.1029/2012GL051447.

Sohn, B.-J., S. Lee, E.-S. Chung, and H.-J. Song, 2016: The role of the dry static stability for the recent change in the Pacific
Walker circulation. J. Climate, 29, 2765-2779, https://doi.org/ 10.1175/JCLI-D-15-0374.1.

Solomon, A., and M. Newman, 2012: Reconciling disparate twentieth-century Indo-Pacific ocean temperature trends in the instrumental record. Nat. Climate Change, 2, 691-699, https://doi.org/10.1038/nclimate1591.

Sun, D.-Z., and Z. Liu, 1996: Dynamic ocean-atmosphere coupling: A thermostat for the tropics. Science, 272, 1148-1150, https:// doi.org/10.1126/science.272.5265.1148.

Taylor, K. E., R. J. Stouffer, and G. A. Meehl, 2012: An overview of CMIP5 and the experiment design. Bull. Amer. Meteor. Soc., 93, 485-498, https://doi.org/10.1175/BAMS-D-11-00094.1.

Thompson, D. W., J. J. Kennedy, J. M. Wallace, and P. D. Jones, 2008: A large discontinuity in the mid-twentieth century in observed global-mean surface temperature. Nature, 453, 646649, https://doi.org/10.1038/nature06982.

Tokinaga, H., S.-P. Xie, A. Timmermann, S. McGregor, T. Ogata, H. Kubota, and Y. M. Okumura, 2012a: Regional patterns of tropical Indo-Pacific climate change: Evidence of the Walker circulation weakening. J. Climate, 25, 1689-1710, https:// doi.org/10.1175/JCLI-D-11-00263.1.

_ — C C. Deser, Y. Kosaka, and Y. M. Okumura, 2012b: Slowdown of the Walker circulation driven by tropical IndoPacific warming. Nature, 491, 439-443, https://doi.org/10.1038/ nature11576.

Vecchi, G. A., and B. J. Soden, 2007: Global warming and the weakening of the tropical circulation. J. Climate, 20, 43164340, https://doi.org/10.1175/JCLI4258.1.

$\longrightarrow,-$ A. T. Wittenberg, I. M. Held, A. Leetmaa, and M. J. Harrison, 2006: Weakening of tropical Pacific atmospheric circulation due to anthropogenic forcing. Nature, 441, 73-76, https://doi.org/10.1038/nature04744.

Xie, S.-P., C. Deser, G. A. Vecchi, J. Ma, H. Teng, and A. T. Wittenberg, 2010: Global warming pattern formation: Sea surface temperature and rainfall. J. Climate, 23, 966-986, https://doi.org/ 10.1175/2009JCLI3329.1.

Yang, C., and B. S. Giese, 2013: El Niño Southern Oscillation in an ensemble ocean reanalysis and coupled climate models. J. Geophys. Res. Oceans, 118, 4052-4071, https://doi.org/ 10.1002 /jgrc. 20284.

Yasunaka, S., and K. Hanawa, 2011: Intercomparison of historical sea surface temperature datasets. Int. J. Climatol., 31, 10561073, https://doi.org/10.1002/joc.2104.

Yu, Z., P. S. Schopf, and J. P. McCreary Jr., 1997: On the annual cycle of upper-ocean circulation in the eastern equatorial Pacific. J. Phys. Oceanogr., 27, 309-324, https://doi.org/ 10.1175/1520-0485(1997)027<0309:OTACOU >2.0.CO;2.

Zebiak, S. E., and M. A. Cane, 1987: A model El Niño-Southern Oscillation. Mon. Wea. Rev., 115, 2262-2278, https://doi.org/ 10.1175/1520-0493(1987)115<2262:AMENO>2.0.CO;2. 